\title{
Fabrication of Laminated Spark Plasma Sintered Compacts Composed of Alumina-Particle-Dispersed Magnesium and Magnesium
}

\author{
Shigehiro Kawamori ${ }^{1}$, Hiroshi Fujiwara ${ }^{2}$, Yoshinori Nagai ${ }^{3}$ and Yukio Kasuga ${ }^{1}$ \\ ${ }^{1}$ Department of Engineering Design, Tamagawa University, Tokyo 194-8610, Japan \\ ${ }^{2}$ Department of Mechanical Engineering, Shizuoka Institute of Science and Technology, Fukuroi 437-8555, Japan \\ ${ }^{3}$ Press Kogyo Co., Ltd., Fijisawa 252-0816, Japan
}

\begin{abstract}
To reduce the weight of 20 vol\% $\mathrm{Al}_{2} \mathrm{O}_{3}$-particle-dispersed $\mathrm{Mg}\left(\mathrm{Al}_{2} \mathrm{O}_{3} / \mathrm{Mg}\right)$ compacts produced by spark plasma sintering (SPS), which are much harder than practical high strength $\mathrm{AZ} 91 \mathrm{Mg}$ alloys, 20/0/20 vol\% laminated SPS compacts sandwiching a lightweight 0 vol\% $\mathrm{Al}{ }_{2} \mathrm{O}_{3} / \mathrm{Mg}$ $(0 \mathrm{vol} \%)$ layer between two $20 \mathrm{vol} \% \mathrm{Al}_{2} \mathrm{O}_{3} / \mathrm{Mg}(20 \mathrm{vol} \%)$ layers were fabricated by a mechanical milling/SPS process, and their microstructures and mechanical properties were investigated. The density of the $20 / 0 / 20$ vol\% laminated SPS compacts was $1.88 \mathrm{Mg} \cdot \mathrm{m}^{-3}$, and they could be lightened to approximately $80 \%$ of the weight of equivalent $20 \mathrm{vol} \%$ SPS compacts. The $20 / 0 / 20$ vol $\%$ laminated SPS compacts had a slightly higher hardness than the $20 \mathrm{vol} \%$ SPS compacts and a much higher hardness than AZ91 alloys. The bending strength of the $20 / 0 / 20$ vol\% laminated SPS compacts was almost the same as that of the 20 vol\% SPS compacts, and was higher than the value calculated from those of the 20 and 0 vol $\%$ SPS compacts using the rule of mixtures. A new phase appeared at the flat interface between the 20 and 0 vol\% layers with excellent adhesion to the adjoining layers, so this phase probably had a strong effect on the bending strength of the $20 / 0 / 20 \mathrm{vol} \%$ laminated SPS compacts. The new phase generated a monotonically decreasing hardness gradient from the 20 vol\% layer to the 0 vol $\%$ layer and was formed by diffusion of $\mathrm{Al}$ and $\mathrm{O}$ from the 20 vol\% layer and diffusion of $\mathrm{Mg}$ from the 0 vol\% layer. The new phase most likely consisted of $\alpha \mathrm{Mg}$, $\mathrm{MgO}$, and $\mathrm{Mg}_{17} \mathrm{Al}_{12}$, and the concentrations of $\mathrm{Al}$ in the $\alpha \mathrm{Mg}, \mathrm{MgO}$, and $\mathrm{Mg}_{17} \mathrm{Al}_{12}$ components of this phase were considered to decrease from the $20 \mathrm{vol} \%$ layer to the 0 vol\% layer. [doi:10.2320/matertrans.M2016289]
\end{abstract}

(Received August 19, 2016; Accepted November 21, 2016; Published December 26, 2016)

Keywords: mechanical milling, alumina-particle-dispersed magnesium, laminated spark plasma sintering compact, different phase, hardness, bending strength

\section{Introduction}

In recent years, advances in automotive weight reduction have led to an increase in the demand for $\mathrm{Mg}$ alloys as lightweight substitutes for $\mathrm{Al}$ alloys. However, $\mathrm{Mg}$ alloys generally have inferior mechanical properties such as hardness, $0.2 \%$ proof stress, the tensile strength and bending strength compared to Al alloys. To improve these mechanical properties, composites of pure $\mathrm{Mg}$ reinforced by ceramic particles have been fabricated using powder metallurgical processes, and their mechanical properties have been investigated ${ }^{1-4)}$.

In a previous study ${ }^{5-7)}$, we prepared $\mathrm{Al}_{2} \mathrm{O}_{3}$ particles uniformly dispersed in pure $\mathrm{Mg}\left(\mathrm{Al}_{2} \mathrm{O}_{3} / \mathrm{Mg}\right)$ powders by mechanical milling $(\mathrm{MM})$ powder mixtures of pure $\mathrm{Mg}$ powder and $0-30$ vol\% $\mathrm{Al}_{2} \mathrm{O}_{3}$ particles, and then investigated the mechanical properties of compacts obtained from these $\mathrm{Al}_{2} \mathrm{O}_{3}$ / $\mathrm{Mg}$ powders by spark plasma sintering (SPS). The 20 and 30 vol\% $\mathrm{Al}_{2} \mathrm{O}_{3} / \mathrm{Mg}$ SPS compacts had a higher hardness (over $200 \mathrm{HV}$ ) than practical high-strength AZ91 Mg alloys ${ }^{8)}$. Furthermore, the $20 \mathrm{vol} \% \mathrm{Al}_{2} \mathrm{O}_{3} / \mathrm{Mg}(20 \mathrm{vol} \%)$ SPS compacts had a higher bending strength than the 0 vol\% $\mathrm{Al}_{2} \mathrm{O}_{3}$ / $\mathrm{Mg}(0 \mathrm{vol} \%)$ SPS compacts. However, the light weight of the $\mathrm{Al}_{2} \mathrm{O}_{3} / \mathrm{Mg}$ SPS compacts disappears with increasing the $\mathrm{Al}_{2} \mathrm{O}_{3}$ content because the density of $\mathrm{Al}_{2} \mathrm{O}_{3}\left(3.9-4.0 \mathrm{Mg} \cdot \mathrm{m}^{-3}\right)$ is more than twice that of $\mathrm{Mg}\left(1.74 \mathrm{Mg} \cdot \mathrm{m}^{-3}\right)$.

In the present study, to reduce the weight of the $20 \mathrm{vol} \%$ SPS compacts, 20/0/20 vol\% laminated SPS compacts sandwiching a lightweight 0 vol\% $\mathrm{Al}_{2} \mathrm{O}_{3} / \mathrm{Mg}(0 \mathrm{vol} \%)$ layer between two $20 \mathrm{vol} \% \mathrm{Al}_{2} \mathrm{O}_{3} / \mathrm{Mg}(20 \mathrm{vol} \%$ ) layers were fabricated using an MM/SPS process, and their microstructures and mechanical properties were investigated.

\section{Experimental Procedure}

Pure Mg powder (180- $\mu$ m particle size; Kojundo Chemical Laboratory Co., Ltd.; purity: $99.5 \%)$ and $\alpha-\mathrm{Al}_{2} \mathrm{O}_{3}$ particles (1- $\mu$ m particle size; Kojundo Chemical Laboratory Co., Ltd.; purity: $99.9 \%$ ) were used as starting materials. Powder mixtures of the $\mathrm{Mg}$ powder and $20 \mathrm{vol} \% \mathrm{Al}_{2} \mathrm{O}_{3}$ particles were fed into an $\mathrm{Al}_{2} \mathrm{O}_{3}$ container together with 5-mm-diameter $\mathrm{Al}_{2} \mathrm{O}_{3}$

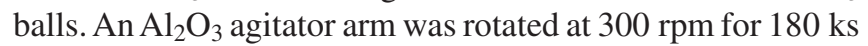
in an $\mathrm{Ar}$ atmosphere to mill the mixed powders. 4 mass\% stearic acid was added as a lubricant. $\mathrm{Mg}$ powder without $\mathrm{Al}_{2} \mathrm{O}_{3}$ particles was also subjected to the same treatment.

The 20 vol\% $\mathrm{Al}_{2} \mathrm{O}_{3}$-particle-dispersed $\mathrm{Mg}$ (20 vol\%) powder and the $\mathrm{Mg}(0 \mathrm{vol} \%)$ powder were obtained by the above process. Figure 1 shows cross-sectional SEM images of the 20 vol\% powder. The MM treatment decreased the particle size of the initial $\mathrm{Mg}$ powders and distributed fine $\mathrm{Al}_{2} \mathrm{O}_{3}$ particles homogeneously throughout the $\mathrm{Mg}$ powder.

Figure 2 shows the procedure for producing laminated SPS compacts with a 20/0/20 vol\% layered structure. Given weights of 0 and $20 \mathrm{vol} \%$ powders were measured out, and the powders were placed in a graphite die $(20-\mathrm{mm}$ inner di-
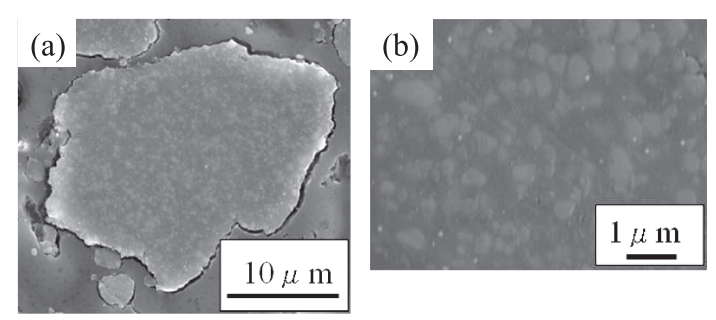

Fig. 1 Cross-sectional SEM image (a) and higher magnification (b) of 20 vol\% $\mathrm{Al}_{2} \mathrm{O}_{3}$-particle-dispersed $\mathrm{Mg}$ powder. 
ameter) in the order of 20,0 , and $20 \mathrm{vol} \%$ and compacted at $20 \mathrm{MPa}$ using a hydraulic press.

The laminated green compacts with a three-layered structure of 20/0/20 vol\% powders were densified in the graphite die using an SPS apparatus (DR. SINTER LAB ${ }^{\mathrm{TM}}$ SPS-515S; Fuji Electronic Industrial Co., Ltd.) at $40 \mathrm{MPa}$ and $848 \mathrm{~K}$ for $0.6 \mathrm{ks}$ in an Ar atmosphere. The graphite die was then cooled to below $323 \mathrm{~K}$ in the SPS apparatus to obtain laminated SPS compacts with a layered structure of $20 / 0 / 20 \mathrm{vol} \% \mathrm{Al}_{2} \mathrm{O}_{3}$ / Mg (20/0/20 vol\% laminated SPS compacts).

The 20/0/20 vol\% laminated SPS compacts were finished by adjusting their thickness by emery polishing and buffing both surfaces until the volume ratio of the 20 vol\% layers to the 0 vol\% layers was 1 to 4 . For comparison, 0 and 20 vol\% SPS compacts were also fabricated using the process shown in Fig. 2.

Microstructural observations and qualitative analysis of the $\mathrm{Al}_{2} \mathrm{O}_{3} / \mathrm{Mg}$ powders and SPS compacts were performed using optical microscopy, SEM-EDS, and XRD. The surface and cross-sectional hardnesses of the $\mathrm{Al}_{2} \mathrm{O}_{3} / \mathrm{Mg}$ SPS compacts were measured using a Vickers hardness tester at $49 \mathrm{~N}$ for $10 \mathrm{~s}$ and a micro-Vickers hardness tester at $0.098 \mathrm{~N}$ for $10 \mathrm{~s}$, respectively. Bending specimens were given prescribed dimensions by electric discharge machining of the $\mathrm{Al}_{2} \mathrm{O}_{3} / \mathrm{Mg}$ SPS compacts. After buffing both surfaces of the specimens, three-point bending tests were conducted at a crosshead speed of $2.0 \mathrm{~mm} / \mathrm{min}$. The bending strengths were calculated from the obtained maximum loads using the general formula ${ }^{9)}$.

\section{Results and Discussions}

\subsection{Cross-sectional observation of $20 / 0 / 20$ vol\% lami- nated SPS compacts}

Figure 3 shows a cross-sectional optical micrograph of the $20 / 0 / 20$ vol\% laminated SPS compact. The two ends and the central region were the 20 and 0 vol\% layers, respectively, and an new phase appeared at the interface between the 20 and 0 vol\% layers. The approximate thickness of the new phase was a nearly constant $40 \mu \mathrm{m}$.

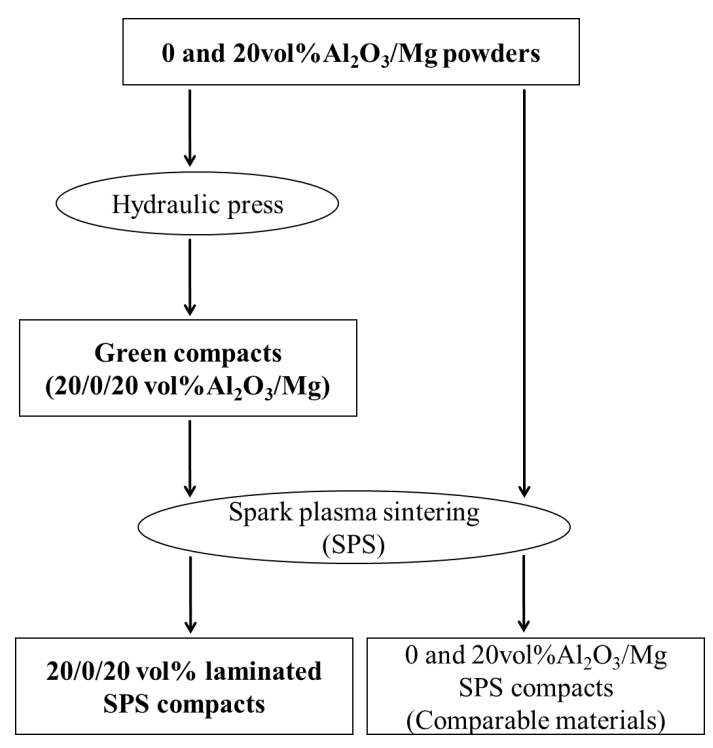

Fig. 2 Fabrication process for laminated SPS compacts.

\subsection{Characteristics of $20 / 0 / 20$ vol\% laminated SPS compacts}

Figure 4 shows XRD results from the surfaces of 20/0/20 vol\% laminated SPS compacts and from separate 20 and 0 vol $\%$ SPS compacts. From these results, the constituent phase of the $0 \mathrm{vol} \%$ SPS compact was identified as $\mathrm{Mg}$ and $\mathrm{MgO}^{5-7)}$.

The surface (20 vol\%) layer of the 20/0/20 vol\% laminated SPS compact was identified as $\mathrm{Mg}, \mathrm{Al}_{2} \mathrm{O}_{3}, \mathrm{MgO}$, and $\mathrm{Mg}_{17} \mathrm{Al}_{12}$, which is identical to that of the 20 vol\% SPS compact ${ }^{5-7)}$. During SPS, $\mathrm{Mg}_{17} \mathrm{Al}_{12}$ is formed in the $20 \mathrm{vol} \%$ layer by solid-phase reaction between $\mathrm{Mg}$ and $\mathrm{Al}_{2} \mathrm{O}_{3}{ }^{5-7)}$. If the $\mathrm{Al}-\mathrm{Mg}$ binary phase diagram ${ }^{10)}$ is applied to the solid-phase reaction of $\mathrm{Mg}$ and $\mathrm{Al}_{2} \mathrm{O}_{3}$, the following reaction might occur at the interfaces between the $\mathrm{Mg}$ and $\mathrm{Al}_{2} \mathrm{O}_{3}$ particles in the 20 vol\% layer.

$53 \mathrm{Mg}+7 \mathrm{Al}_{2} \mathrm{O}_{3} \rightarrow 15 \mathrm{Mg}+2 \mathrm{Al}+\mathrm{Mg}_{17} \mathrm{Al}_{12}+21 \mathrm{MgO}$

Here, it was estimated that the solid solubility limit of $\mathrm{Al}$ in $\mathrm{Mg}$ was $11.5 \mathrm{~mol} \% \mathrm{Al}$ at a reaction temperature of $710 \mathrm{~K}^{10)}$. $\mathrm{Al}$ and $\mathrm{O}$ decompose at the interfaces between the $\mathrm{Mg}$ and $\mathrm{Al}_{2} \mathrm{O}_{3}$ particles, $\mathrm{Al}$ dissolves in $\mathrm{Mg}$, and $\mathrm{O}$ produces $\mathrm{MgO}$ in response to $\mathrm{Mg}$. $\mathrm{Mg}_{17} \mathrm{Al}_{12}$ is produced when the solid solution of $\mathrm{Mg}$ and $\mathrm{Al}(\alpha \mathrm{Mg})$ exceeds the solid solubility limit of $\mathrm{Al}$ in $\mathrm{Mg}^{5-7)}$.
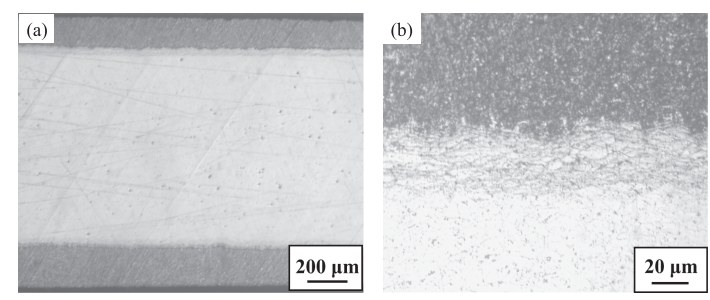

Fig. 3 Cross-sectional optical macrograph (a) and higher magnification (b) of a 20/0/20 vol\% laminated SPS compact. The volume ratio of $20 \mathrm{vol} \%$ $\mathrm{Al}_{2} \mathrm{O}_{3} / \mathrm{Mg}$ to 0 vol\% $\mathrm{Al}_{2} \mathrm{O}_{3} / \mathrm{Mg}$ was 4 to 1 .

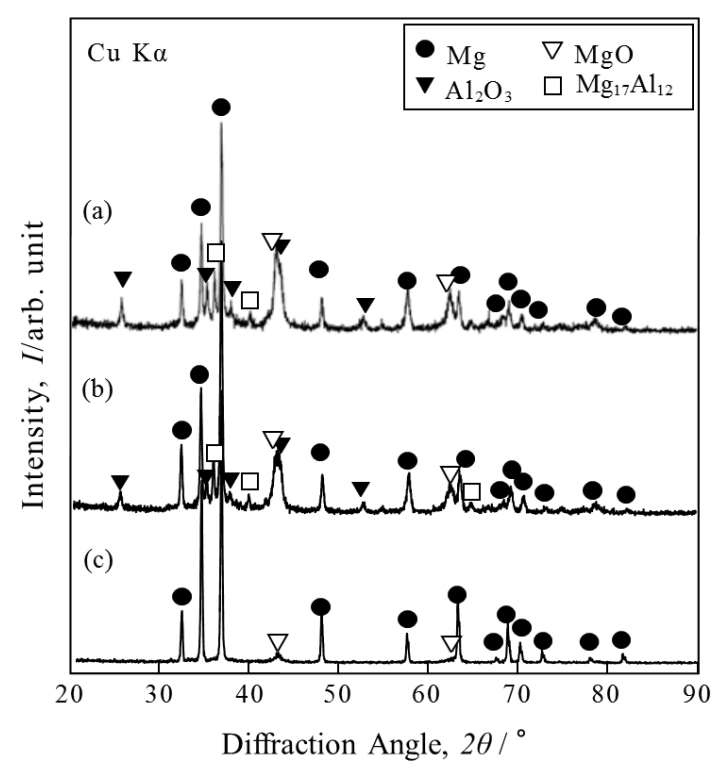

Fig. 4 XRD results from the surfaces of $20 / 0 / 20$ vol\% laminated (a), 20 vol\% (b), and 0 vol\% (c) SPS compacts. 
Though $\mathrm{MgAl}_{2} \mathrm{O}_{4}$ (Spinel) is also estimated to product by the solid-phase reaction of $\mathrm{MgO}$ and $\mathrm{Al}_{2} \mathrm{O}_{3}$ particles, it is difficult to identify Spinel by XRD and TEM-EDS. Therefore, it is considered that there is very little production of Spinel.

Figure 5 shows the densities of 20/0/20 vol\% laminated SPS compacts, $20 \mathrm{vol} \%$ SPS compacts, and 0 vol $\%$ SPS compacts. The density of the laminated SPS compact was $1.88 \mathrm{Mg} \cdot \mathrm{m}^{-3}$, or approximately $80 \%$ of the $20 \mathrm{vol} \%$ SPS compacts $\left(2.28 \mathrm{Mg} \cdot \mathrm{m}^{-3}\right)$. The densities of the laminated SPS compacts were almost the same as the values calculated from those of the 20 and 0 vol\% SPS compacts using the rule of mixtures. Here, the calculated values were defined as the range of values that includes the new phase to 0 or $20 \mathrm{vol} \%$ layers.

Figure 6 shows Vikers hardness and specific hardness values of 20/0/20 vol\% laminated SPS compacts, 20 vol\% SPS compacts, and 0 vol $\%$ SPS compacts. The laminated SPS compacts had a slightly higher hardness than the $20 \mathrm{vol} \%$ SPS compacts, $215 \mathrm{HV}$, which is much higher than that of AZ91 Mg alloys ${ }^{8)}$, as shown in Fig. 6(a).

Some paper ${ }^{1-3)}$ about the mechanical properties of ceramics particle strengthened pure Mg matrix composites fabricated using powder metallurgical processes has listed the Vikers hardness values of $65 \mathrm{HV}-179 \mathrm{HV}$.

To express both lightness and high hardness of the laminated SPS compacts, "specific hardness" was defined as the Vikers hardness per density. The laminated SPS compacts had a higher "specific hardness" than the 20 vol\% SPS compacts, as shown in Fig. 6(b).

Figure 7 shows the bending strength and specific strength of 20/0/20 vol\% laminated, $20 \mathrm{vol} \%$, and $0 \mathrm{vol} \%$ SPS compacts. The bending strengths of the laminated SPS compacts were almost the same as those of the 20 vol\% SPS compacts, and were higher than the expected values calculated from the strengths of the 20 and 0 vol\% SPS compacts using the same method used to calculate the density, as shown in Fig. 7(a).

The specific strength was defined as the bending strength

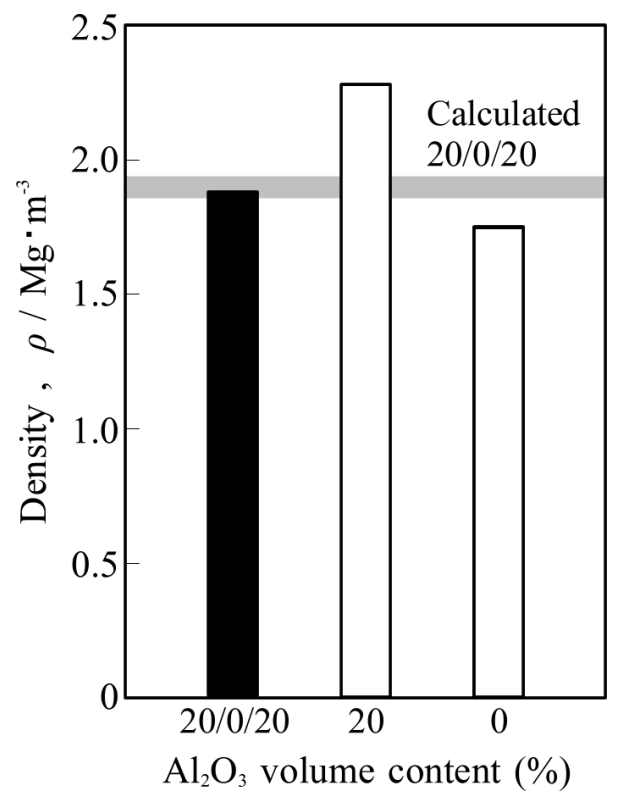

Fig. 5 Densities of 20/0/20 vol\% laminated, 20 vol $\%$, and 0 vol $\%$ SPS compacts. per density. The laminated SPS compacts had a higher specific strength than the 20 and 0 vol\% SPS compacts, as shown in Fig. 7(b).

Figure 8 shows an cross-sectional optical micrograph of a 20/0/20 vol\% laminated SPS compact fractured by the bending test. The adhesion between the new phase and both $\mathrm{Al}_{2} \mathrm{O}_{3} /$ $\mathrm{Mg}$ layers was excellent, as no abrasion was observed at their interfaces, as shown in Figs. 8(a)-8(d).

If the bending strength of the 20 and 0 vol\% layers is assumed to satisfy the rule of mixtures, then the bending strengths of the $20 / 0 / 20 \mathrm{vol} \%$ laminated, $20 \mathrm{vol} \%$ and 0 vol\% SPS compacts can be used to obtain the bending strength of the new phase as follows:

$$
\sigma_{20 / 0 / 20}=\sigma_{20} V_{20}+\sigma_{0} V_{0}+\sigma_{\text {a.p. }} V_{\text {a.p. }},
$$

which can be rearranged to

$$
\sigma_{\text {a.p. }}=\left(\sigma_{20 / 0 / 20}-\sigma_{20} V_{20}-\sigma_{0} V_{0}\right) / V_{a . p .},
$$
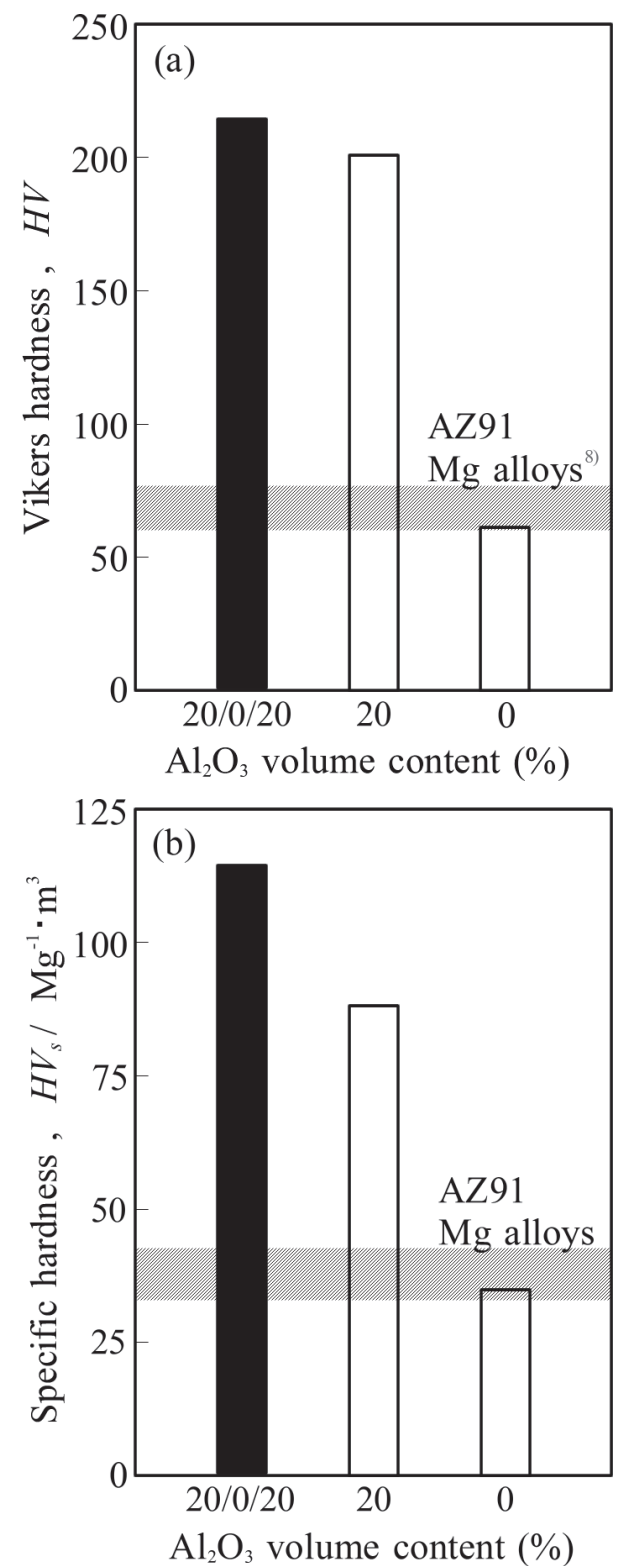

Fig. 6 Vikers hardness (a) and specific hardness (b) of 20/0/20 vol\% laminated, $20 \mathrm{vol} \%$, and 0 vol $\%$ SPS compacts. 
where $\sigma_{\text {a.p. }}$ is the bending strength of the new phase, $\sigma_{20 / 0 / 20}$, $\sigma_{20}$, and $\sigma_{0}$ are the bending strengths of the $20 / 0 / 20 \mathrm{vol} \%$ laminated compact, 20 vol\% SPS compact, and 0 vol $\%$ SPS
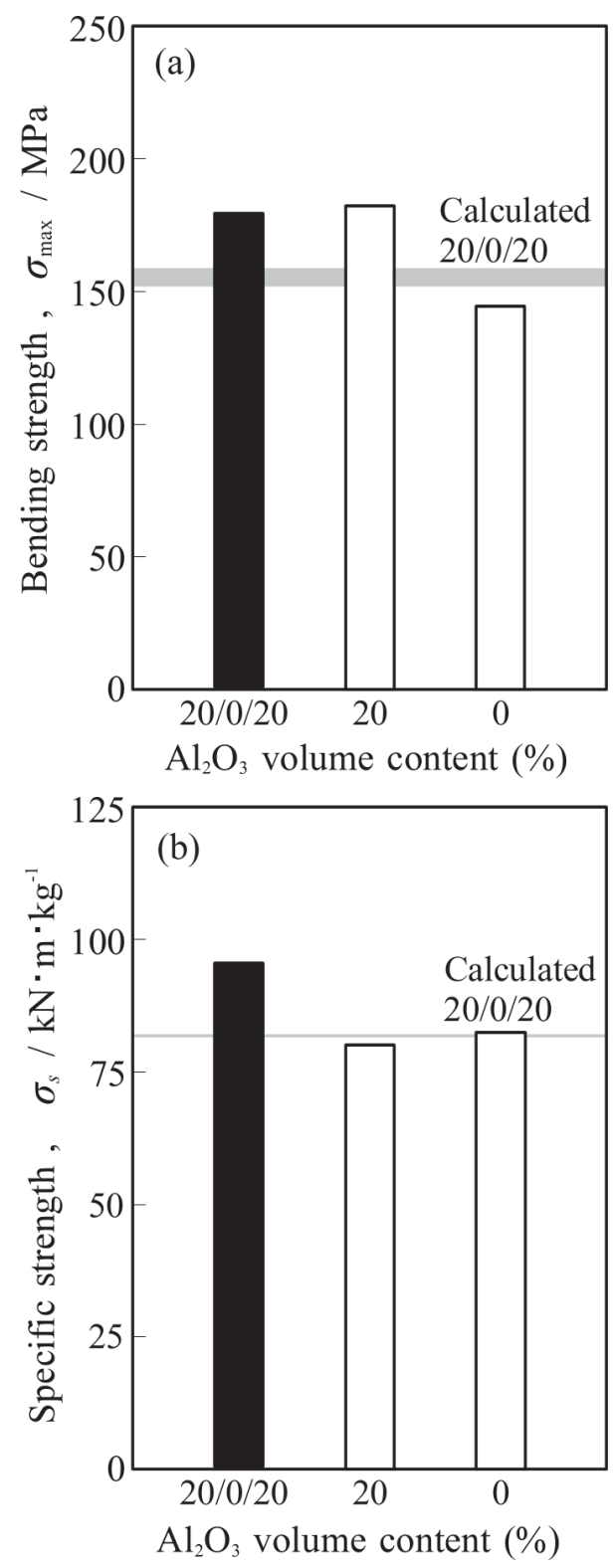

Fig. 7 Bending strength (a) and specific strength (b) of 20/0/20 vol\% laminated, $20 \mathrm{vol} \%$, and 0 vol $\%$ SPS compacts.
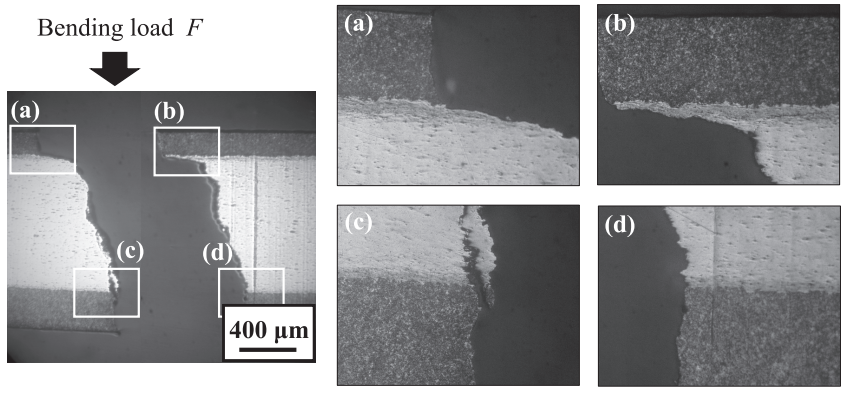

$100 \mu \mathrm{m}$

Fig. 8 Cross-sectional optical macrograph of 20/0/20 vol\% laminated SPS compact fractured by the bending test. compact, respectively, $V_{a . p .}$ is the volume fraction of the new phase, and $V_{20}$ and $V_{0}$ are the volume fractions of the $20 \mathrm{vol} \%$ and 0 vol\% SPS compacts.

Using eq. (3), the bending strength of the new phase $\sigma_{a . p}$. was calculated to be approximately $600 \mathrm{MPa}$, which is more than triple those of the $20 \mathrm{vol} \%$ SPS compacts. Therefore, the new phase should have a strong effect on the bending strength of the 20/0/20 vol\% laminated SPS compacts.

\subsection{The new phase at the interface between $20 / 0 / 20$ vol\% $\mathrm{Al}_{2} \mathrm{O}_{3} / \mathrm{Mg}$ layers}

To investigate the new phase in detail, micro-Vikers hardness tests and SEM-EDS line analysis were conducted over cross-sections of the laminated SPS compacts. Figures 9(a) and 9(b) show an optical macrograph and micro-Vikers hardness distribution of the cross-section of a 20/0/20 vol\% laminated SPS compact, respectively. The results shows that the hardness of the new phase decreased monotonically from the 20 vol\% layer to the 0 vol\% layer. Here, the space of the hardness measurement position is smaller than a rule of JIS (Z2244), but it is thought that there is little effect of the measurement space on the hardness value because the hardness value measured at the space according to the rule did not almost same as the value of Fig. 9 (b). Therefore, it may be said that there is little effect of the work- hardening on the hardness values.

Figures 10(a) and 10(b) show a cross-sectional SEM micrograph and SEM-EDS line analysis results for a $20 / 0 / 20$ vol\% laminated SPS compact, respectively. In the new phase, the EDS profile of $\mathrm{Mg}$ tended to decrease from the 0 vol\% layer to the 20 vol\% layer. Moreover, $\mathrm{Al}$ and $\mathrm{O}$ were detected in the phase. Therefore, the new phase was formed by the diffusion of $\mathrm{Al}$ and $\mathrm{O}$ from the $20 \mathrm{vol} \%$ layer and $\mathrm{Mg}$ from the 0 vol\% layer.

From the above results, we propose a mechanism for the formation of the new phase in the 20/0/20 vol\% laminated compacts. Prior to SPS, the 20 vol $\%$ layer in the $20 / 0 / 20$ vol $\%$ laminated green compacts consists of $\mathrm{Mg}, \mathrm{Al}_{2} \mathrm{O}_{3}$, and $\mathrm{MgO}$,

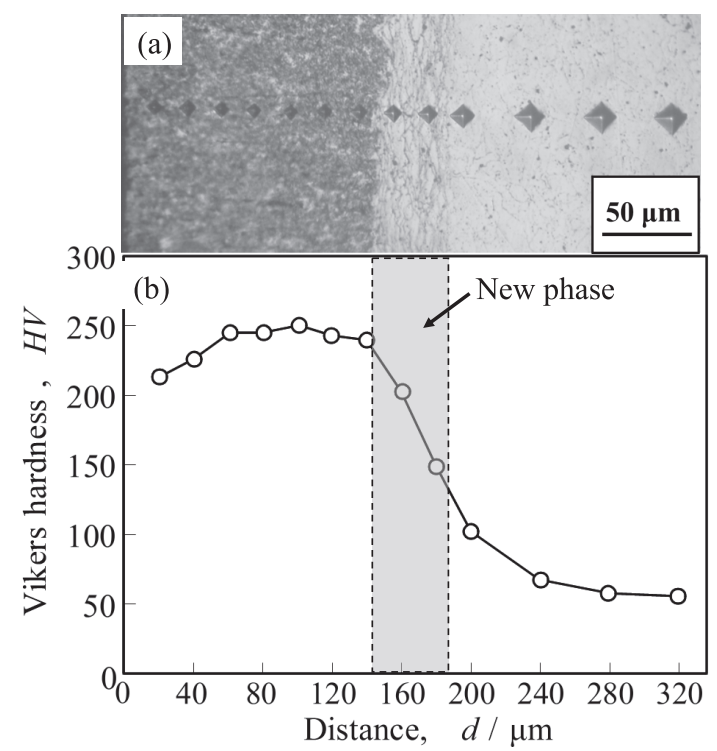

Fig. 9 Optical macrograph (a) and micro-Vikers hardness distribution (b) of the cross-section of a 20/0/20 vol\% laminated SPS compact. 


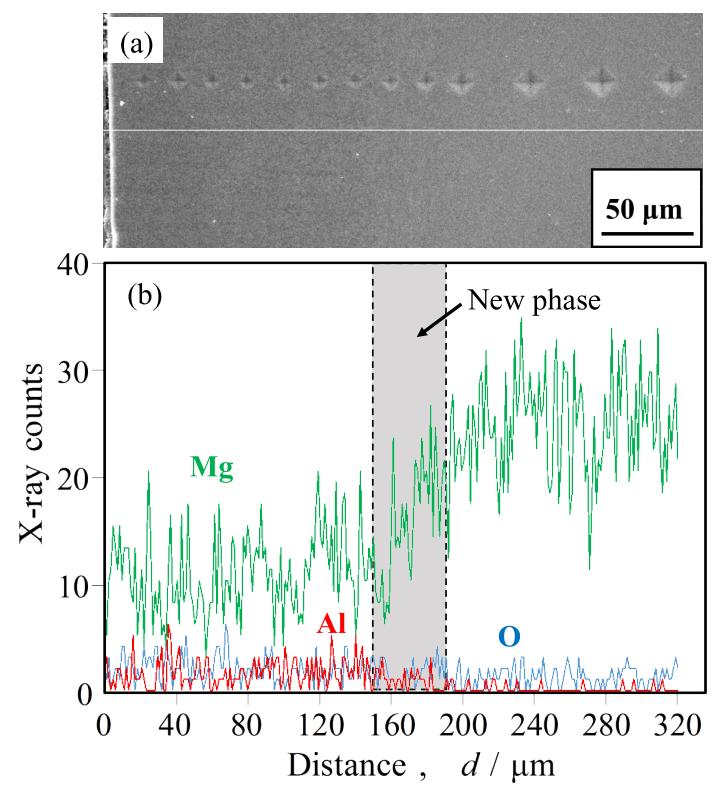

Fig. 10 SEM micrograph (a) and SEM-EDS line analysis results (b) for cross-section of a 20/0/20 vol\% laminated SPS compact.

whereas the 0 vol\% layer consists of $\mathrm{Mg}$ and $\mathrm{MgO}$ according to the XRD results. Then, during SPS, because of the previously mentioned solid-phase reaction between the $\mathrm{Mg}$ and $\mathrm{Al}_{2} \mathrm{O}_{3}$ particles ${ }^{5-7)}$, the $\mathrm{Al}$ and $\mathrm{O}$ atoms that decomposed from the $\mathrm{Al}_{2} \mathrm{O}_{3}$ particles at the edge of the 20 vol\% layer near the interface between the 20 and 0 vol\% layers diffuse into the 0 vol\% layer, which contains no $\mathrm{Al}_{2} \mathrm{O}_{3}$ particles. Meanwhile, $\mathrm{Mg}$ at the edge of the 0 vol\% layer near the interface between the 20 and 0 vol\% layers diffuses into the 20 vol\% layer, in which the $\mathrm{Mg}$ concentration is less than that of the $0 \mathrm{vol} \%$ layer. Consequently, the new phase formed during the SPS. Finally, after SPS, the newly formed phase likely consists of $\alpha \mathrm{Mg}, \mathrm{MgO}$, and $\mathrm{Mg}_{17} \mathrm{Al}_{12}$, and the concentrations of $\mathrm{Al}$ in $\alpha \mathrm{Mg}, \mathrm{MgO}$, and $\mathrm{Mg}_{17} \mathrm{Al}_{12}$ in the phase is considered to decrease from the $20 \%$ layer to the $0 \%$ layer. As mentioned previously, it is considered that there is very little production of Spinel.

Because the atomic radii of $\mathrm{Mg}(0.160 \mathrm{~nm})$ and $\mathrm{Al}$ $(0.143 \mathrm{~nm})$ are similar ${ }^{11)}$, the effect of the solid-solution strengthening of $\mathrm{Mg}$ due to the increase of $\mathrm{Al}$ on the hardness distribution of the new phase should be small. However, a strong negative hardness gradient is generated from the $20 \%$ layer to the $0 \%$ layer in the new phase, as can be seen in Fig. 9.

Therefore, the primary cause of the large hardness gradient along the new phase is probably a decrease in the production of $\mathrm{MgO}$ and $\mathrm{Mg}_{17} \mathrm{Al}_{12}$ from the $20 \%$ layer to the $0 \%$ layer.

\section{Conclusion}

20 vol\% $\mathrm{Al}_{2} \mathrm{O}_{3}$-particle-dispersed $\mathrm{Mg}\left(\mathrm{Al}_{2} \mathrm{O}_{3} / \mathrm{Mg}\right)$ SPS compacts have a much higher hardness than the conventional AZ91 high strength $\mathrm{Mg}$ alloy, but are also heavier. To reduce their weight, laminated SPS compacts sandwiching a lightweight 0 vol\% $\mathrm{Al}_{2} \mathrm{O}_{3} / \mathrm{Mg}(0 \mathrm{vol} \%)$ layer between two highstrength $20 \% \quad \mathrm{Al}_{2} \mathrm{O}_{3} / \mathrm{Mg}$ (20 vol\%) layers (20/0/20 vol\% laminated SPS compacts) were fabricated using an MM/SPS process and their microstructures and mechanical properties were investigated. The following results were obtained:

(1) The density of the $20 / 0 / 20$ vol\% laminated SPS compacts was $1.88 \mathrm{Mg} \cdot \mathrm{m}^{-3}$ and their weights could be reduced to approximately $80 \%$ of the weight of an equivalent 20 vol\% SPS compact.

(2) The laminated SPS compacts had a slightly higher hardness than the 20 vol\% SPS compacts and were much harder than AZ91 Mg alloys.

(3) The bending strength of the laminated SPS compacts was similar to that of the $20 \mathrm{vol} \%$ SPS compacts and was higher than the value calculated based on those of the 20 and 0 vol $\%$ SPS compacts.

(4) A new phase was formed at the flat interface between the $20 \mathrm{vol} \%$ and $0 \mathrm{vol} \%$ layers. The adhesion between the new phase and both layers was excellent, and this phase is thought to have a strong effect on the bending strength of the laminated SPS compacts.

(5) The new phase most likely consists of $\alpha \mathrm{Mg}, \mathrm{MgO}$, and $\mathrm{Mg}_{17} \mathrm{Al}_{12}$, and the concentrations of $\mathrm{Al}$ in the $\alpha \mathrm{Mg}$, $\mathrm{MgO}$, and $\mathrm{Mg}_{17} \mathrm{Al}_{12}$ in the phase is considered to decrease from the $20 \%$ layer to the $0 \%$ layer.

\section{Acknowledgments}

This work was supported by JSPS KAKENHI Grant Number JP15K05688.

\section{REFERENCES}

1) H. Ferkel and B.L. Mordike: Mater. Sci. Eng. A 298 (2001) 193-199.

2) A. Yamazaki, J. Kaneko and M. Sugamata: J. Jpn. Soc. Powder Powder Metall. 48 (2001) 61-66.

3) A. Yamazaki, J. Kaneko and M. Sugamata: J. Jpn. Soc. Powder Powder Metall. 48 (2001) 397-403.

4) Z. Drozd and Z. Trojanova: Mater. Sci. Forum 567-568 (2008) 189192.

5) S. Kawamori, H. Fujiwara, K. Kuroda and Y. Kasuga: Steel Research International Special ed. (2012) 823-826.

6) S. Kawamori, H. Fujiwara and Y. Kasuga: Mater. Sci. Forum 783-786 (2014) 2433-2438.

7) H. Fujiwara, S. Hamanaka, S. Kawamori and H. Miyamoto: Mater. Trans. 55 (2014) 543-548.

8) M. M. Avedesian and H. Baker: Magnesium and Magnesium Alloys, (ASM International, Ohio, 1999) p.231.

9) H. Sudo: Materials Testing, (Uchida Rokakuho Publishing Co., Ltd., 1998) pp.61-62.

10) H. Okamoto: Phase Diagrams for Binary Alloys Second Edition, (ASM International, Ohio, 2010) p. 36.

11) Y. Waseda et al.: Metal Data Book, (The Japan Institute of Metals and Materials, Sendai, 2008) p.8. 